\title{
Congenital adrenal hyperplasia in a 66-year-old female
}

\author{
A. D. WRIGHT* \\ M.B., F.R.C.P. \\ G. Holder $\dagger$ \\ B.Sc., M.Sc.
}

\author{
T. C. HARVEY** \\ M.B., M.R.C.P. \\ D. C. ANDERSON $\ddagger$ \\ M.D., F.R.C.P.
}

\author{
B. T. RudD $\dagger$ \\ Ph.D., B.Sc., F.I.M.L.S.
}

${ }^{*}$ General Hospital, Birmingham B4 6NH, **The Manor Hospital, Walsall, $\uparrow$ Endocrine Laboratory, The Birmingham \& Midland Women’s Hospital, and $\ddagger$ Hope Hospital, Pendleton, Salford

\begin{abstract}
Summary
A 66-year-old genotypically female patient was reared as a man. Investigations showed a partial adrenal 21hydroxylase deficiency, and pituitary gonadotrophin secretion typical of a post-menopausal woman.
\end{abstract}

\section{Introduction}

Congenital adrenal hyperplasia in female infants is frequently recognized at birth or soon after puberty and treated with glucocorticoids. The patient presented here is unusual in that the defect was severe enough for him to be raised as a man, but mild enough to be living without glucocorticoid treatment at the age of 63 when the first biochemical investigations were done. The clinical features of this case are almost identical to the first clear record of congenital adrenal hyperplasia in a patient who was reared as a male and lived to the age of 43 years (de Crecchio, 1865; quoted by Bongiovanni and Root, 1963). Modern investigations in such long-lived untreated patients are inevitably limited to occasional case reports (Ishida et al., 1976; Van't Hoff and Bicknell, 1972). The present patient provides evidence that sexual differences in gonadotrophin secretion are maintained despite hypothalamic exposure to excess androgens in uterine and early post-natal life.

\section{Case history}

The patient was born in 1912 and first presented with acute vertigo in 1975 . There was doubt about his sex at birth, and he was initially considered female and given the name Rachel. Later he was thought to be male, his name was revised to Ronald

*Address for reprints. and he was reared as a boy. He grew rapidly until the age of 11 years, excelling at athletics, having normal male interests and remaining physically very strong until aged approximately 45 years. His work often involved heavy manual labour. Haematuria never occurred. Throughout life he has had normal male interests and has been married twice. One sister died of convulsions at birth, whilst his brother was normal until he died of a brain tumour at the age of 47 years. There was a maternal cousin of uncertain sex, but no further details could be obtained.

On examination, height was $1.49 \mathrm{~m}$ and weight $51.5 \mathrm{~kg}$. He had a normal masculine configuration with marked balding, normal facial hair requiring daily shaving, sparse body hair and a female escutcheon. There was no gynaecomastia and BP was normal $(140 / 85 \mathrm{mmHg})$. External genitalia showed a $3 \mathrm{~cm}$ phallus, unfused labioscrotal folds, a single urogenital sinus and a vaginal orifice. No gonads were palpable.

\section{Investigations}

$\mathrm{X}$-rays showed extensive degenerative changes throughout the spine but a normal pituitary fossa. Computerized axial tomography of the abdomen failed to demonstrate the adrenal glands. Normal female karyotype was found on lymphocyte culture with Giemsa banding studies. Serum electrolytes were normal. Basal measurements of various steroids were performed before and after Celite column chromatography. Total androgens (mainly testosterone and dihydrotestosterone) were measured by the method of Glass et al. (1976); progesterone by the method of Shaw et al. (1974); 17 $\alpha$-hydroxyprogesterone by the method of Davila et al. (1980); 
cortisol, Morris (1978); 17ß-oestradiol, Shaw et al. (1974); dehydroepiandrosterone sulphate, Smith et al. (1975). Plasma ACTH was measured by radioimmunoassay (Rees and Landon, 1976). The steroid analyses after Celite column chromatography (Anderson et al., 1976) have been corrected to $100 \%$ recovery.

Table 1 documents the basal steroid hormone concentrations in serum before and after dexamethasone. The basal investigations showed elevated serum levels of 17-hydroxyprogesterone, progesterone and total androgens and the majority of the raised steroid concentrations returned to normal after dexamethasone. Stimulation with tetracosactrin (Table 2) and measurement of fractionated urinary steroids (Morris and Leeson, 1969), urinary cortisol (Beardwell, Burke and Cope, 1968). and serum cortisol, resulted in an increase of serum and urinary cortisol concentrations with a decrease in the urinary 11-deoxy/11-oxy steroid ratio. Betaglư⿱亠幺 curonidase hydrolysis of urinary glucuronides followed by silica gel chromatography of the steroids extracted from the hydrolysate, revealed tetrahydro derivatives of cortisol and cortisone bu not tetrahydro-11-deoxycortisol.

Basal serum gonadotrophins were elevated an in the post-menopausal range but showed somse suppression after oestrogen administration (Tab 3). After $100 \mu \mathrm{g}$ i.v. of luteinizing hormone-releasing hormone, the gonadotrophins showed a pattern of response that was normal (Mortimer et al., 1973).

\section{Discussion}

The investigations favoured a diagnosis of adren 21-hydroxylase deficiency. Interpretation of the steroid results, however, may depend upon thie? specificity of the assay. Although the serum cortisot analysis may include some cross reaction witR

TABLE 1. Serum steroid levels

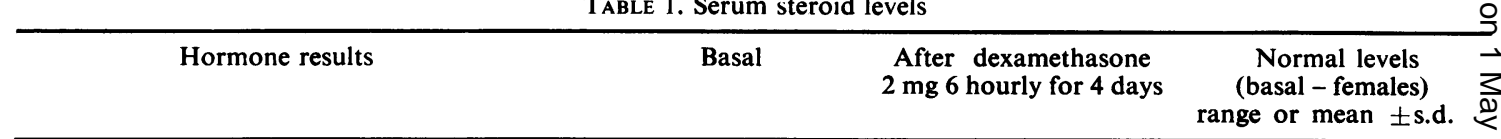

9 a.m. АCTH (ng/l)

Steroids (without chromatography)

Progesterone (nmol/l)

$17 \alpha$-hydroxyprogesterone $(\mathrm{nmol})$

Total androgens (nmol/l)

Dehydroepiandrosterone sulphate $(\mu \mathrm{mol} / \mathrm{l})$

9 a.m. cortisol (nmol/1)

Oestradiol-17 $\beta$ (pmol/l)

After celite chromatography

Pregnenolone (nmol/l)

Progesterone (nmol/l)

$17 \alpha$-hydroxypregnenolone $(\mathrm{nmol} / \mathrm{l})$

$17 \alpha$-hydroxyprogesterone $(\mathrm{nmol} / \mathrm{l})$

Dehydroepiandrosterone $(\mathrm{nmol} / \mathrm{l})$

Androstenedione ( $\mathrm{nmol} / \mathrm{l})$

Androstenediol (nmol/l)

Testosterone (nmol/l)

40,72
25,29
280
10,12
$3 \cdot 0$
340,430

170

\begin{tabular}{cc}
37 & $1 \cdot 3$ \\
$9 \cdot 8$ & $6 \cdot 5$ \\
102 & - \\
3.0 & - \\
$15 \cdot 1$ & $3 \cdot 5$ \\
$7 \cdot 5$ & $1 \cdot 7$ \\
14.0 & $1 \cdot 8$ \\
\hline
\end{tabular}

5

$2 \cdot 4$

$1 \cdot 6$

30

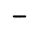

$<4<10-80$

$<10^{*}$

$1-6 \cdot 8^{*}$

$2 \cdot 4-5 \cdot 8 \dagger$

$0 \cdot 5-1 \cdot 4 \dagger$

140-700

$<100 \dagger$

$9 \cdot 7 \pm 5 \cdot 6$

$1 \cdot 7 \pm 1 \cdot 0$

$10 \cdot 8 \pm 7 \cdot 8$

$1 \cdot 3 \pm 1 \cdot 2$

$26 \cdot 4 \pm 14 \cdot 2$

$6 \cdot 1+2 \cdot 5$

$7 \cdot 6 \pm 4 \cdot 7$

$0.8 \pm 0.5$

* Follicular; $\dagger$ post menopausal.

TABLE 2. Urinary steroids and serum cortisol

\begin{tabular}{|c|c|c|c|c|c|c|}
\hline \multirow[b]{2}{*}{ Urine } & \multicolumn{2}{|c|}{ Dexamethasone suppression } & \multicolumn{3}{|c|}{ Tetracosactrin stimulation } & \\
\hline & Basal & $\begin{array}{c}\text { After } 2 \mathrm{mg} \\
6 \text { hrly for } \\
4 \text { days }\end{array}$ & Basal & $\begin{array}{l}\text { After } 0.5 \mathrm{mg} \\
\text { 3rd day }\end{array}$ & $\begin{array}{l}\text { twice daily } \\
\text { 4th day }\end{array}$ & range \\
\hline 11-deoxyfraction ( $\mu \mathrm{mol} /$ day) & 54 & 18 & 178 & 490 & 580 & $1 \cdot 5-10$ \\
\hline 11-oxyfraction ( $\mu \mathrm{mol} / \mathrm{day})$ & 31 & 13 & 81 & 236 & 435 & $7-24$ \\
\hline $11 \mathrm{deoxy} / \mathrm{oxy}$ ratio & $1 \cdot 7$ & $1 \cdot 4$ & $2 \cdot 2$ & $2 \cdot 1$ & $1 \cdot 3$ & $<0.9$ \\
\hline Free cortisol (nmol/day) & 57 & $<30$ & 70 & 340 & 250 & $<30-420$ \\
\hline 9 a.m. serum cortisol $(\mathrm{nmol} / \mathrm{l})$ & - & - & 320 & 2190 & 1720 & $140-700$ \\
\hline
\end{tabular}


cortisone, 21-deoxycortisol and 11-deoxycortisol, only cortisone cross-reacted to an appreciable extent $(28.4 \%)$ in this assay. Furthermore, the silica gel chromatography of an extract of urine after glucuronidase hydrolysis revealed only metabolites of

TABLE 3. Pituitary-gonadal function

\begin{tabular}{ccc}
\hline & $\begin{array}{c}\text { Serum FSH } \\
(\mathrm{u} . / \mathrm{l})\end{array}$ & $\begin{array}{c}\text { Serum LH } \\
(\mathrm{u} . / \mathrm{l})\end{array}$ \\
\hline Basal mean (range) & $41(39-43)$ & $20(14-24)$ \\
On oestrogens* & & \\
Day 5 & 34 & 18 \\
Day 6 & 25 & 19 \\
Day 7 & 26 & 26 \\
Day 8 & 24 & 20 \\
Day 9 & 22 & 13 \\
Day 10 & 20 & 11 \\
After LHRH ${ }^{\dagger}$ & & \\
30 min & 50 & 72 \\
$60 \mathrm{~min}$. & 49 & 77 \\
\hline
\end{tabular}

*Ethinyl oestradiol $20 \mu \mathrm{g}$. daily from day 0 to day 10 with a single i.m. injection of $1 \mathrm{mg}$ oestradiol benzoate on day 5 .

$\dagger$ Luteinizing hormone releasing hormone $100 \mu \mathrm{g}$ i.v.

cortisol and not 11-deoxycortisol. However, using a combination of specific radioimmunoassay and competitive protein binding assay 11-deoxycortisol $(15.9 \mathrm{nmol} / \mathrm{l})$ and 21-deoxycortisol $(70.5 \mathrm{nmol} / \mathrm{l})$ were present in the serum. It is suggested therefore that both the 11- and 21-hydroxylase enzyme systems were partially functioning and that some of the cortisol found in the serum could have arisen from 21-hydroxylation of 21-deoxycortisol. It has been well documented that cortisol secretion rates may be within the normal range in congenital adrenal hyperplasia (Migeon and Kenny, 1966). The rise in serum cortisol on tetracosactrin and the presence of metabolites of cortisol in the urine, is further evidence that the enzyme block is partial (Galal, Rudd and Drayer, 1968). The normal plasma Nterminal ACTH concentration was unexpected because in patients with untreated congenital adrenal hyperplasia it is invariably raised (Rees, 1977) and is above the upper limit of normal in $50 \%$ of the treated cases (Pham-Huu-Trung et al., 1978). Perhaps with a partial enzyme block and very long-standing adrenal hyperplasia the normal ACTH levels were sufficient to maintain normal cortisol secretion with normal negative feedback. However, it is also possible that to obtain a true picture of the relationship of ACTH and cortisol more frequent serum sampling is required as ACTH secretion is episodic in normals and in patients with untreated congenital adrenal hyperplasia (Fukushima et al., 1975).

Both assays for $17 \alpha$-hydroxyprogesterone showed clearly elevated levels, thus the cross reactions of
$17 \alpha$-hydroxypregnenolone $(9 \cdot 5 \%)$, progesterone $(5.0 \%)$ and 11 -deoxycortisol $(6.8 \%)$ in the nonchromatographic method did not significantly affect the interpretation of the result. The striking elevation of $\Delta^{4}$-androstenedione is consistent with other reports (Horton and Frasier, 1967; Rudd and Rayner, 1970) of raised levels of this adrenal steroid in untreated male and female patients, and adds strength to the definitive diagnosis of 21-hydroxylase deficiency.

Basal serum gonadotrophins tend to be normal or suppressed in female patients with congenital adrenal hyperplasia (Kirkland et al., 1974; Bacon, Spencer and Kelch, 1976). Low levels were measured in a 31-year-old untreated patient reared as a male (Ishida et al., 1976). The high levels in the serum of the present patient may be due to 'his post-menopausal' age. Investigations of prepubertal and adolescent patients with luteinizing hormonereleasing hormone tests have demonstrated that there is a normal sex difference in FSH secretion in patients with congenital adrenal hyperplasia (Reiter et al., 1975; Richards et al., 1978) and that androgen imprinting of the hypothalamus in prenatal and neonatal life does not occur in man. The suppression of gonadotrophins by oestrogen administration in the present patient is similar to that found in the normal post-menopausal woman treated with ethinyl oestradiol over longer periods of time (Larsson-Cohn et al., 1977).

\section{Acknowledgments}

This case was presented at a meeting of the Section of Endocrinology, Royal Society of Medicine.

We would like to thank Prof. L. H. Rees for measuring the plasma ACTH, and Prof. R. B. Brooks for performing the specific 11-deoxycortisol and 21-deoxycortisol assays.

\section{References}

ANDERSON, D.C., Hopper, B.R., LAsley, B.L. \& Yen, S.S.C. (1976) A simple method for the assay of eight steroids in small volumes of plasma. Steroids, 28, 179.

Bacon, G.E., SPencer, M.L. \& KelCh, R.P. (1976) Effect of cortisol treatment on hormonal relationships in congenital adrenal hyperplasia. Clinical Endocrinology, 6, 113.

Beardwell, C.G., Burke, C.W. \& Cope, C.L. (1968) Urinary free cortisol measured by competitive protein binding. Journal of Endocrinology, 42, 79.

Bongiovanni, A.M. \& Root, A.W. (1963) The adrenogenital syndrome. New England Journal of Medicine, 268, 1283.

Davila, N., Rudd, B.J., Morris, R., Kandeel, F., Bodden, J. \& LONDON, D.R. (1980). A simple procedure for the radioimmunoassay of $17 \alpha$-hydroxyprogesterone in serum. Comparison with an immunological purification technique. Annals of Clinical Biochemistry, 17, 31.

DE Crecchio, L. (1865) Sopra un caso di apparenze virili in una donna. Morgagni, 7, 151 .

Fukushima, D.K., Finkelstein, J.W., Yoshida, K., Boyar, R.M. \& Hellman, L. (1975) Pituitary adrenal activity in untreated congenital adrenal hyperplasia. Journal of Clinical Endocrinology and Metabolism, 40, 1. 
Galal, O.M., Rudd, B.T. \& Drayer, N.M. (1968) Evaluation of deficiency of 21-hydroxylation in patients with congenital adrenal hyperplasia. Archives of Disease in Childhood, 43, 410.

Glass, M.R., Williams, J.W., Butt, W.R., Edwards, R.L. \& LoNDON, D.R. (1976) Basal serum prolactin values and responses to the administration of thyrotrophin releasing hormone (TRH) in women with amenorrhoea. British Journal of Obstetrics and Gynaecology, 83, 495.

Horton, R. \& Frasier, S.E. (1967) Androstenedione and its conversion to plasma testosterone in congenital adrenal hyperplasia. Journal of Clinical Investigation, 46, 1003.

Ishida, H., Fukutani, K., Imao, S., Hirose, K. \& Isurugi, K. (1976) Pituitary-gonadal function in a female hermaphrodite with congenital adrenal hyperplasia. Journal of Urology, 116, 130.

Kirkland, J., Kirkland, R., Librik, L. \& Clayton, G. (1974) Serum gonadotropin levels in adolescents with congenital adrenal hyperplasia. Journal of Pediatrics, 84, 411.

LARSSON-Cohn, U., JohansSon, E.D.B., Kagadal, B. \& Wallentin, L. (1977) Serum FSH, LH and oestrone levels in post-menopausal patients on oestrogen therapy. British Journal of Obstetrics and Gynaecology, 85, 367.

Migeon, C.J. \& KenNy, F.M. (1966) Cortisol production rate in congenital virilizing adrenal hyperplasia. Journal of Pediatrics, 69, 779.

MorRIS, R. (1978) A simple and economical method for the radioimmunoassay of cortisol in serum. Annals of Clinical Biochemistry, 15, 178.

MoRris, R. \& LeEson, S.A. (1969) A comparison of two methods for the separate estimation of 11-deoxy and 11-oxygenated 17-hydroxycorticosteroids in urine. Journal of Medical Laboratory Technology, 26, 243.

Mortimer, C.H., Besser, G.M., MCNeilly, A.S., Marshall, J.C., Harsoulis, P., Tunbridge, W.M.G., Gomez-Pan, A. \& HALL, R. (1973) The LH and FSH releasing hormone test in patients with hypothalamic-pituitary-gonadal dysfunction. British Medical Journal, 4, 73.

Pham-HuU-Trung, M.T., Gourmelen, M., RanX-Eurin,
M.C. \& GIRARD, F. (1978) Pituitary-adrenal axis activiţ in treated congenital adrenal hyperplasia: static an dynamic studies. Journal of Clinical Endocrinology and Metabolism, 47, 422.

REES, L.H. (1977) ACTH, lipotrophin and MSH in health and disease. Clinics in Endocrinology and Metabolism, 137.

ReES, L.H. \& LANDON, J. (1976) Adrenocorticotroph hormone. In: Hormone Assays and their Clinical Applict? tion (Ed by Loraine, J.A. \& Bell, E.T.), pp. 193-2220 Churchill Livingstone, London.

Reiter, E.O., Grumbach, M.M., Kaplan, S.L. \& Conte F.A. (1975) The response of pituitary gonadotropes to synthetic LRF in children with glucocorticoid-treated. congenital adrenal hyperplasia: lack of effect of ire trauterine and neonatal androgen excess. Journal of Clinical Endocrinology and Metabolism, 49, 318.

Richards, G.E., Grumbach, M.M., KaPlan, S.L. CONTE, F.A. (1978) The effect of long acting glucocorte coids on menstrual abnormalities in patients with virilising congenital hyperplasia. Journal of Clinical Endocrinologis and Metabolism, 47, 1208.

RUDD, B.T. \& RAYNER, P.H.W. (1970) Androgen levels i plasma and urine of patients with virilizing congenita adrenal hyperplasia. Proceedings of the Royal Society $\dot{\alpha} 0$ Medicine, 63, 1039.

Shaw, R.W., Butt, W.R., London, D.R. \& Marshalio J.C. (1974) Variation in response to synthetic luteinizing hormone-releasing hormone (LH-RH) at different phases of the same menstrual cycle in normal women. Journ of Obstetrics and Gynaecology of the British Commore wealth, 81, 632 .

SMith, M.R., Rudd, B.T., Shirley, A., Rayner, P.H.gV $\overrightarrow{0}$ Williams, J.W., Duignan, N.M. \& Bertrand, ofve (1975) A radioimmunoassay for the estimation of serm dehydroepiandrosterone sulphate in normal and pa鬲e logical sera. Clinica chimica acta, 65, 5 .

VAN'T HofF, W. \& BiCKNell, E.J. (1972) Congenital adrena杂 hyperplasia and diabetes mellitus. Acta endocrinologico 69, 329. 